\title{
Sick veterans pin hopes on Gulf War inquiry
}

David Osumi-Sutherland, London

How should an illness with no clearly defined symptoms or cause be dealt with? That's the challenge emerging from a UK inquiry into the illnesses facing veterans of the first Gulf War. Soldiers who fought in the conflict are falling sick in surprisingly high numbers, researchers have told the inquiry. Yet experts say there is no definable 'Gulf War syndrome' nor any obvious reason for the symptoms.

The inquiry has been running in London since 6 July, in response to requests by former service personnel. Organized by Alf Morris, a Labour member of the House of Lords who is sympathetic to the veterans' case, it does not have government backing. But former senior army personnel and former employees of the Ministry of Defence have given evidence.

Several large-scale epidemiological studies have been run on veterans of the 1990-91 war and all have revealed significant increases in disease. A study of almost 10,000 UK veterans, for example, found that $24 \%$ suffered health problems ( $\mathrm{N}$. Cherry et al. Occup. Environ. Med. 58, 291-298; 2001), $14 \%$ higher than in a control group of some 5,000 who did not serve in the Gulf.

A wide range of symptoms, from headaches and diarrhoea to memory loss, were reported, ruling out post-traumatic stress disorder. But this diversity made it impossible for the survey's lead author, Nicola Cherry of the University of Alberta in Edmonton, Canada, to distinguish a specific group of symptoms to characterize the condition.

Identifying a cause for the high rates of illhealth has proved just as difficult. Experts at the inquiry have focused on two possibilities: exposure to nerve gas, and the medication given to soldiers before the war.

Robert Haley of the Southwestern Medi-

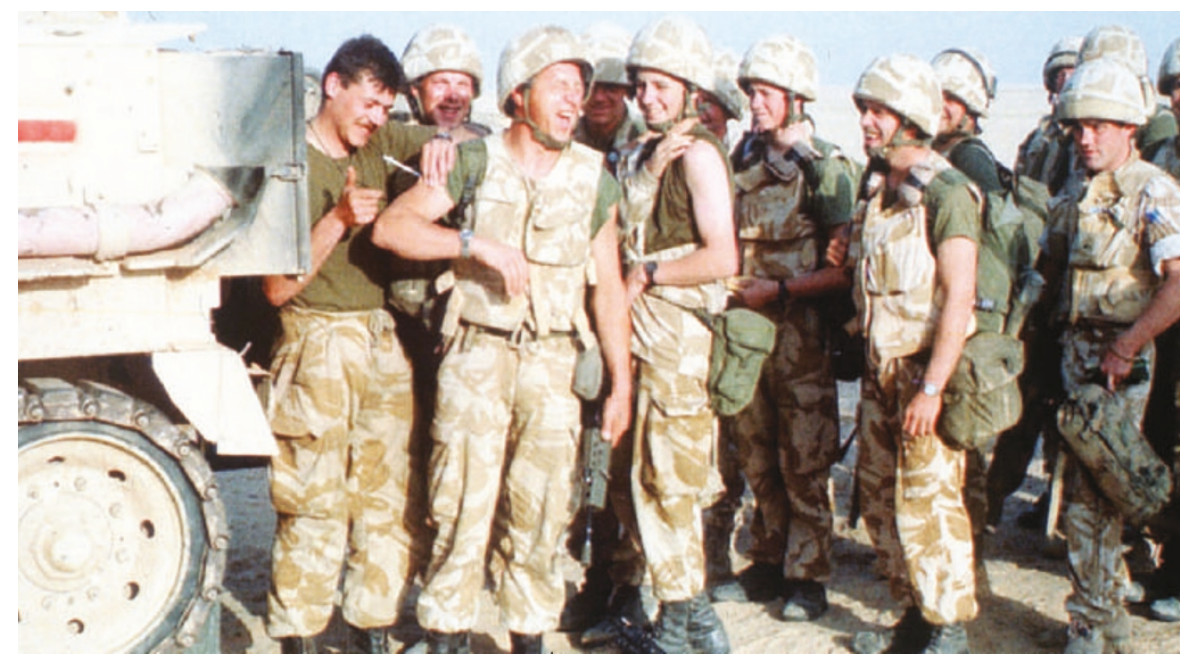

Call to arms: could vaccinations be the cause of increased illness among British Gulf War veterans?

cal School at Dallas, Texas, cited US government studies estimating that up to 100,000 US troops could have been exposed to low levels of the nerve gas sarin when an ammunition dump at Khamisiyah in southern Iraq was bombed. A study revealed changes in the brains of sick veterans, which he says are consistent with low-level sarin poisoning (R.W. Haley et al. Radiology 215, 807-817;2000).

Other witnesses dispute Haley's hypothesis. "Sarin is a deadly substance," says Simon Wessely, a psychiatrist at King's College London. Any exposure, he argues, would have resulted in deaths, but none were recorded.

Wessely adds that epidemiological studies show no link between illness levels and the area of the Gulf where the soldiers served, suggesting that researchers should focus on a factor that applied to all veterans. One possibility, he says, is pyrodostigmine bromide tablets, taken regularly by troops to protect against nerve-gas attack. This is hard to study, as records of its use were not kept. But Wessely says that troops given multiple vaccinations in the Gulf are more likely to be ill than those who had the same shots at home. He speculates that the risk factor may be a combination of stress and the vaccinations.

The Ministry of Defence denies that Gulf War syndrome exists. Some 2,500 war pensions have been awarded, but that figure includes payments for all injuries sustained in the conflict. Yet if Cherry's analysis is extrapolated to the 45,000 troops who fought in the Gulf, more than 6,000 extra UK soldiers could have become ill because of the war.

"Veterans are finding it hard to get the medical treatment that they need," says Terry English, director of welfare at the Royal British Legion, which campaigns on behalf of ex-servicepeople. "This should be given a high priority."

The inquiry, chaired by former law lord Anthony Lloyd, is due to end in October.

\section{Plan for light relay sparks heated opposition}

\section{Mark Peplow, London}

The idea was to "unite all nations by the enlightening power of physics". But with eight months to go, Max Lippitsch's plans have succeeded only in dividing his colleagues.

Lippitsch, a physicist at the KarlFranzens University in Graz, Austria, wants to shine a relay of lights around the Earth to celebrate the World Year of Physics 2005. But astronomers say the scheme sanctions light pollution, the needless illumination of the night sky that increasingly interferes with their observations.

Britain's Institute of Physics pulled out of the project late last month. "Astronomers were very concerned," says Caitlin Watson, who is managing the institute's contribution to the year's celebrations. "Even though this won't produce much light pollution, it sets a very bad precedent."

The World Year of Physics celebrates the centenary of Albert Einstein's "miraculous year", which saw him lay the foundations for the theory of relativity, quantum theory and the theory of brownian motion. The goal is to boost the public awareness of physics.

The light relay is set to begin on 18 April next year in Princeton, New Jersey, the 50th anniversary of Einstein's death. Participants will shine torches to neighbouring groups up to 10 kilometres away, who will then switch on their lights. This domino effect should ripple around the Earth, with undersea fibre-optic cables linking continents. Lippitsch says that the light pollution will be tiny because high-powered searchlights and lasers are banned.

But Vinaya Sathyasheelappa, the World Year of Physics project coordinator for the American Physical Society, says there are "mixed emotions" about the project in the United States. He adds that the society is nonetheless likely to back it: "Without the United States the light would have to go through Canada, and Canada's physics society just doesn't have the resources to make this work." 